\title{
The Influence of Base Oil Properties on the Friction Behaviour of Lithium Greases in Rolling/Sliding Concentrated Contacts
}

\author{
N. De Laurentis ${ }^{1}$ (1) P. Cann ${ }^{1} \cdot$ P. M. Lugt ${ }^{2} \cdot$ A. Kadiric $^{1}$
}

Received: 17 May 2017/ Accepted: 7 August 2017/Published online: 28 August 2017

(C) The Author(s) 2017. This article is an open access publication

\begin{abstract}
This study investigates the influence of base oil type and viscosity on the frictional behaviour of lithiumthickened bearing greases. A series of model lithium greases were manufactured by systematically varying viscosity and type of base oil, so that the influence of a single base oil property could be studied in isolation. In addition, selected greases were blended with oleic acid, with the purpose of evaluating its effectiveness in further reducing grease friction. Friction coefficient and film thickness were measured in laboratory ball-on-disc tribometers over a range of speeds and temperatures. For a specific oil type, the influence of base oil viscosity on friction was found to be closely related to its effect on film thickness: greases formulated with PAO oils covering a wide range of viscosities gave very similar friction at the same nominal film thickness. For a given base oil viscosity, base oil type was found to have a strong influence on grease friction under all test conditions. PAO-based greases generally produced lower friction than mineral- and ester-based greases. Addition of oleic acid to the test greases did not significantly affect friction within the range of test conditions employed in this study. The results provide new insight into the frictional behaviour of greases, which may be used to help inform new low-friction grease formulations for rolling bearing applications.
\end{abstract}

Keywords Grease · Rolling bearings · Grease friction . Grease film thickness · EHL

N. De Laurentis

nicola.delaurentis@gmail.com

1 Imperial College London, London, UK

2 SKF RDT, Nieuwegein, The Netherlands

\section{Introduction}

Grease is a multi-phase lubricant consisting of two main components: a fluid, which is typically a lubricating oil, and a solid 'thickener,' usually a metal soap. This composition provides grease with some inherent benefits over lubricating oils including a certain rigidity, which allows grease to stay in place without leaking, as well as sealing abilities. These properties make grease particularly suitable for application in rolling bearings. Indeed, this is by far the most common application of lubricating greases, with more than $90 \%$ of rolling bearings employing grease as the lubricant [1]. Rolling bearings are ubiquitous machine elements used in almost all engineering systems, and across many different sectors of industry and transportation. It is reported that over 50 billion bearings are operating in the world at any time [1]. As a result, the cumulative impact of bearing frictional losses on the energy efficiency and sustainability of mechanical systems is significant. Using a suitable 'low-friction' grease represents one of the most versatile ways of reducing frictional losses in a rolling bearing. The primary role of grease in a rolling bearing is to lubricate the highly stressed, concentrated contacts at the interface between the rolling elements and the raceways of the bearing, where a large contribution to the overall friction is generated. Such concentrated contacts operate in the elastohydrodynamic lubrication (EHL) regime. The mechanisms of lubricant film formation, and to a lesser extent friction, in these EHL contacts are relatively well known for oils. However, largely owing to the complex composition of greases, the equivalent mechanisms for greases are still relatively unclear. Although a number of different mechanisms have been proposed specifically for rolling bearings [2-6], a comprehensive, universally accepted theory does not yet exist. 
This is particularly true for grease friction which is the subject of significantly fewer studies than grease film thickness.

Existing grease studies utilising standard laboratory single-contact tests strongly suggest that grease thickener properties have a significant influence on grease friction. For example, certain types of thickeners have been reported to be able to adhere on the surface and form a thin residual layer of deposited thickener particles [6-8], while other studies suggest that, during the lubrication process, grease is mechanically degraded and transforms into a Newtonian suspension of thickener particles in oil, with a higher viscosity than that of the base oil alone $[9,10]$. Therefore, thickener type [4, 11], concentration [12] and thickener particle dimensions [13] appear to have a strong influence on film formation and consequently affect friction by determining the lubrication regime. Grease studies employing real rolling bearings appear to paint a more mixed picture on the influence of individual grease components on bearing friction: some report that the thickener does participate in the lubrication process of bearings [5, 13-16], while others suggest that the most relevant grease component in determining bearing friction is the base oil, with base oil viscosity being the most significant property $[17,18]$. Some of the apparent inconsistencies in the existing grease friction literature are to be expected, given the fact that research on grease friction has been conducted using a great variety of grease formulations and test set-ups, from single-contact laboratory rigs to full bearing tests. As a consequence, the comparison of results across these studies is not always possible and can be deceptive.

Given their inherently greater control over test conditions, single-contact tests allow for more fundamental studies to be carried out, and consequently, provided the conditions are representative of those found in real bearings, can offer improved understanding of the general grease lubrication mechanisms. In particular, studies employing a ball-on-disc setup, which simulates one of the concentrated contacts in a rolling bearing, have generally agreed that in grease lubrication there exist two operating 'regions' in terms of both friction and film thickness behaviour: a 'low-speed' region where the thickener clearly contributes significantly to the lubrication process, and a 'high-speed' region where the oil properties are more important [19-22]. However, of these studies only a few have been methodical in terms of carefully isolating each variable in the grease formulation so that its individual influence on the overall grease tribological behaviour could be investigated in detail. The few existing works adopting this methodology have focussed on the influence of thickener, in particular thickener type [20, 22] and concentration [12].
To address some of these gaps in our understanding of grease friction, the present study attempts to assess the influence of base oil properties on grease friction through a methodical approach of using model greases where a single base oil property is varied at a time while keeping other aspects of formulation consistent. In a previous, related work by the present authors [19], the frictional behaviour of a series of fully formulated, commercially available greases was studied on ball-on-disc tribometers, with the aim of shedding some light on to the effect of grease composition on friction in concentrated contacts. The selection of greases purposely included formulations with different thickener types, and base oil types and viscosities. The results revealed very different friction trends between the greases, as evident in Fig. 1 reproduced from the same work [19]. The most effective 'low-friction' formulation in that investigation was a specific lithium-thickened PAO grease, denoted in that work as LiPAO. However, the grease formulations in that study differed from each other by a large number of variables, hence making it difficult to draw concrete conclusions in terms of specific influence of individual grease components on the overall frictional grease behaviour. Moreover, the study was inevitably affected by a number of uncertainties regarding the exact composition of commercial greases, with only basic information provided by the manufacturers and little known on the base oil type, thickener percentage, additives and manufacturing cycle. The current work eliminates some of these limitations, by testing custom greases fabricated with a known composition and manufacturing process. Given the complex structure of lubricating greases, many aspects of grease formulation can affect friction and not all can be studied at once. The focus of this paper is the influence of base oil viscosity and type on grease friction. These two variables were isolated by comparing greases made with the same type of base oil (PAO and mineral) but different viscosities, or with different oil types (PAO, mixed PAO/ester and mineral) but with similar viscosities. Lithium 12-hydroxystearate, which in the previous study showed low-friction properties in the 'lowspeed' region [19], was used as the thickener, with fixed concentration, for all the greases studied in this paper. The effect of friction modifiers was investigated separately, by additising selected greases and base oils with oleic acid. The use of custom greases with systematically varying composition, combined with tightly controlled test conditions, allows for the influence of single components and/or properties under investigation to be directly assessed. The detailed information obtained in this study can help to inform the development of future low-friction grease formulations. 
Fig. 1 Friction coefficient of commercial greases against entrainment speed at $40{ }^{\circ} \mathrm{C}$ (adapted from [19])

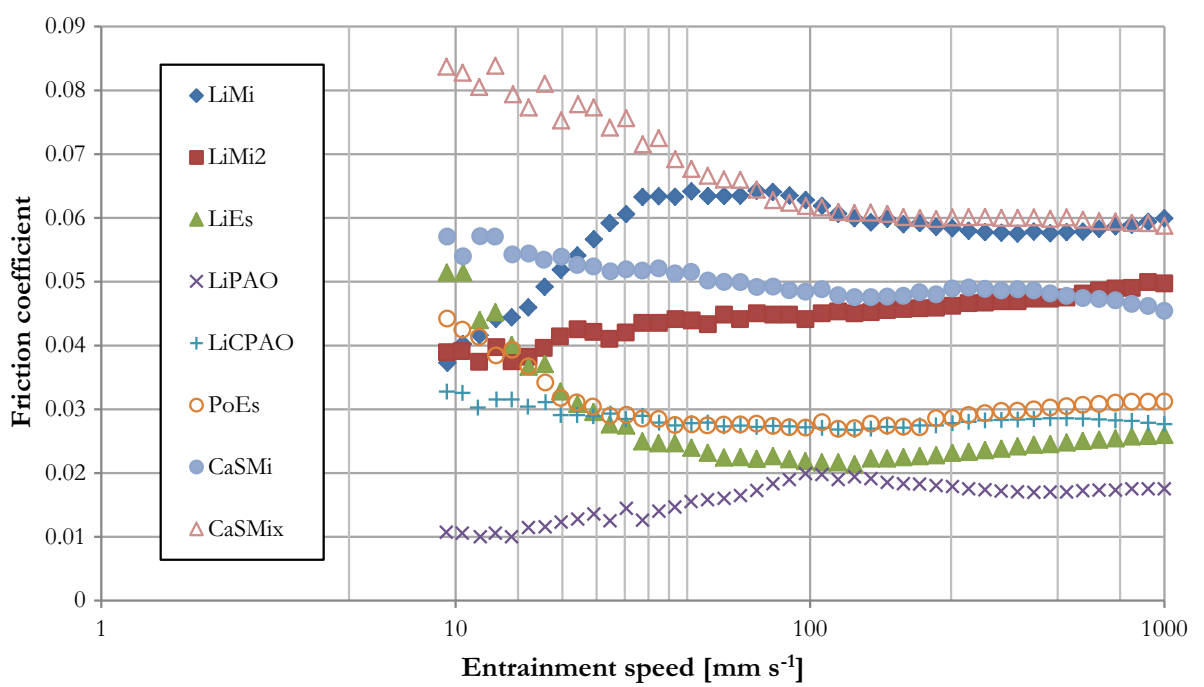

\section{Methodology}

\subsection{Grease Formulations and Manufacturing of Test Samples}

The list of custom greases and their technical data are presented in Table 1. A grease kettle for small batch production, consisting of a reactor connected to a heating and cooling system, was used to fabricate the custom greases. The same general recipe, including the actual quantity of ingredients, and manufacturing protocol, were used for all the greases. The aim was to keep constant manufacturing conditions, so as to maintain consistent results. Since the focus of this work was the influence of base oil properties, all the greases were fabricated using the same amount of 12 w/w\% lithium 12-hydroxystearate thickener. This was produced through the saponification reaction between 12-hydroxystearic acid (HSA) and a dispersion of micronsized anhydrous lithium hydroxide $(\mathrm{LiOH})$ particles in mineral oil [23], conducted in the specific base oil chosen for the given grease batch. A common process [24] for simple lithium greases consisting of four consecutive stages (saponification, soap dissolution, re-crystallization and homogenisation) was employed. A reference thermal cycle [23] was followed during the saponification, soap dissolution and re-crystallization stages, which were carried out in the reactor. The last stage, i.e. homogenisation, was conducted in a roller mill and consisted in working the grease between the rollers in successive steps by progressively reducing the rollers gaps, thus increasingly refining the thickener microstructure [24].

Better understanding of the effect of base oil viscosity on friction can only be achieved if greases made of the same base oil type are compared [25]. PAO was chosen as the most suitable oil type for this investigation, due to its definite and consistent composition [26], with consequent improvements in repeatability of the results and validity of the described comparisons. In addition, the use of PAO

Table 1 List of custom greases tested in the present study

\begin{tabular}{llcccc}
\hline Grease name & Base oil & Oil viscosity @ $40{ }^{\circ} \mathrm{C}(\mathrm{cSt})$ & Oil viscosity @ $100{ }^{\circ} \mathrm{C}(\mathrm{cSt})$ & Additive & NLGI no. \\
\hline LP1 & PAO & 26 & 5 & 5 & None \\
LP1a & PAO & 26 & 8 & Oleic acid & Not available \\
LP2 & PAO & 47 & 14 & None & 3 \\
LP3 & PAO & 211 & 28 & None \\
LP4 & PAO & 413 & 50 & None & $2-3$ \\
LP5 & PAO & 26 & 5 & None & 2 \\
LPE & Mixed PAO/ester & 26 & 5 & None \\
LPEa & Mixed PAO/ester & 35 & 5 & Oleic acid \\
LM1 & Mineral & 35 & 5 & Not available \\
LM1a & Mineral & 102 & 11 & None \\
LM2 & Mineral & & 5 & Oleic acid & Not available \\
\hline
\end{tabular}


allowed for a direct comparison between these custom greases and the commercial LiPAO grease, studied in the previous work by the authors [19], which is formulated with the same type of thickener and base oil. Five PAObased greases were fabricated with PAOs of different viscosities. The designation 'LPx' is used throughout this paper to denote these lithium-PAO greases, with ' $x$ ' between 1 and 5 . The viscosities of the base oils were chosen to be distributed in the following way:

$v_{\mathrm{LP} 5} \approx 2 v_{\mathrm{LP} 4} ; \quad v_{\mathrm{LP} 4} \approx 2 v_{\mathrm{LP} 3} ; \quad v_{\mathrm{LP} 3} \approx 2 v_{\mathrm{LP} 2}$
$v_{\mathrm{LP} 2} \approx 2 v_{\mathrm{LP} 1}$

where $v$ is the kinematic viscosity and the subscript identifies each of the five LP greases.

The investigation into the effect of base oil type on friction was carried out by fabricating three further greases with the same lithium thickener. LM1 and LM2 are mineral oil-based greases, and LPE is a mixed PAO/ester-based grease. LM1 and LM2 base oils are group II mineral oils with different viscosities. LPE base oil is made of $20 \mathrm{w} / \mathrm{w} \%$ dibasic ester and $80 \mathrm{w} / \mathrm{w} \%$ PAO (the same as used for LP1). This selection of greases allows for the influence of base oil type to be isolated by comparing greases made with different oil types of the same viscosity value, namely LP1, LPE and LM1 as one comparison group, and LP3 and LM2 as the second one.

In addition, with the aim of assessing the potential influence of friction modifiers, three extra greases were prepared by blending oleic acid, a common friction modifier in oils, with LP1, LPE and LM1 greases using 5\% w/w oleic acid concentration. For ease of reference, the resulting greases are labelled as LP1a, LPEa and LM1a. Finally, the additised base oils of LP1, LPE and LM1 were also prepared with the same concentration of oleic acid and tested for comparison.

The base oil viscosities in Table 1 are the values measured using Anton Paar Stabinger SVM 3001 viscometer. The viscosity was also measured at 60 and $80{ }^{\circ} \mathrm{C}$, as the friction tests were also carried out at these temperatures. The measured viscosities follow Walther's equation (ASTM D341-722) [27], and hence this formula was used to predict the base oil viscosity in the film thickness measurements, which were carried out at ambient temperature.

\subsection{Experimental Equipment and Procedure}

Laboratory ball-on-disc tribometers were used to measure friction and film thickness. Friction was measured on the MTM rig and film thickness on the EHD rig, both supplied by PCS Instruments UK. These rigs and the experimental procedures adopted in the current paper are the same as those described in the previous work by the authors [19].
Therefore, only the basic information is given here, and the reader is referred to the previous publication for full details. Fully flooded conditions were ensured in all tests by the use of a 'grease scoop', which was mounted ahead of the contact so that it continually pushes the test grease back into the rolling track. Friction was measured over a series of temperatures and entrainment speeds at a fixed slide-to-roll ratio of 0.1 . Film thickness was measured to support the investigation into the friction behaviour of the greases, which is the main focus of this study. Every friction and film thickness test for each grease and test conditions was carried out at least twice, with excellent repeatability. All friction and film thickness results were plotted as an average of at least two tests. The test conditions are summarised in Table 2.

The base oils were also tested for comparison under the same conditions. The base oil film thickness measurements were used to estimate the pressure-viscosity coefficient $\alpha$ of each oil, by back-calculation using the HamrockDowson formula [28]. The resulting $\alpha$ values are reported in Table 3. All PAO oils exhibit relatively similar values of $\alpha$, while the corresponding values for the mineral oils of LM1 and LM2 are much higher. The values are comparable with those reported in the literature for these types of oils [29]. Although the pressure-viscosity coefficients are reported to depend on the contact operating conditions [30], in this study they were assumed to be constant within the range of conditions employed, and were later used to estimate film thickness in the friction tests.

\section{Results}

\subsection{Friction}

The friction curves obtained with the custom greases are shown in Fig. 2 at (a) $40{ }^{\circ} \mathrm{C}$, (b) $60{ }^{\circ} \mathrm{C}$ and (c) $80{ }^{\circ} \mathrm{C}$. The majority of the friction curves have the shape of a bell, i.e. the friction coefficient increases with speed up to a maximum value (the curve 'bump'), after which it starts decreasing. This is particularly evident at $80{ }^{\circ} \mathrm{C}$ in Fig. $2 \mathrm{c}$. LPE grease displays a more accentuated bump, due to the relatively large difference between the values of minimum (at low and high speed) and maximum friction (at the bump speed). All the LP greases produce very low friction at all speeds. LM1 and LM2 give overall higher friction coefficients, especially at high speeds.

The comparison in friction behaviour between LP1 and LPE greases and their base oils, representative of the whole range of behaviour observed for this type of analysis, is shown in Figs. 3 and 4 respectively. At low speeds the greases provide much lower friction than their base oils. With increasing speed, the greases and base oils friction 
Table 2 Friction and film thickness test conditions

\begin{tabular}{lll}
\hline Test & Friction & Film thickness \\
\hline Test specimens & AISI 52100 steel disc & Chromium/silica spacer layer-coated glass disc \\
& 19.05 -mm-diameter AISI 52100 steel ball & 19.05 -mm-diameter AISI 52100 steel ball \\
Composite roughness $\mathrm{Rq}(\mathrm{nm})$ & 18.5 & $<10$ \\
Maximum Hertzian pressure $(\mathrm{GPa})$ & 0.96 & 0.52 \\
Temperatures $\left({ }^{\circ} \mathrm{C}\right)$ & 40,60 and 80 & Ambient $(22 \pm 1)$ \\
Slide/roll ratio $=\frac{2 \times\left|U_{1}-U_{2}\right|}{\left(U_{1}+U_{2}\right)}$ & 0.1 & 0 \\
Entrainment (i.e. average) speed range $\left(\mathrm{mm} \mathrm{s}^{-1}\right)$ & $10-1000$ & $5-1000$ \\
\hline
\end{tabular}

Table 3 Base oils pressure-viscosity coefficient $\alpha$ calculated from film thickness measurements

\begin{tabular}{lllllllll}
\hline Grease base oil & LP1 & LP2 & LP3 & LP4 & LP5 & LPE & LM1 & LM2 \\
\hline$\alpha\left(\mathrm{GPa}^{-1}\right)$ & 14.8 & 16.8 & 15.8 & 16.2 & 16.0 & 15.2 & 21.5 & 26.0 \\
\hline
\end{tabular}

curves get closer. The transition of the greases into their base oil-like behaviour appears to occur at the speeds corresponding to the bump of the grease friction curve: at speeds higher than this the grease and base oil friction curves are generally the same. This transition speed increases with temperature and is lower with LPE than with LP1.

To examine the morphology of the lubricant film deposited in the wake of the contact, the friction tests carried out with these greases at $40{ }^{\circ} \mathrm{C}$ were stopped in sequence at speeds of $20 \mathrm{~mm} \mathrm{~s}^{-1}, \quad 50 \mathrm{~mm} \mathrm{~s}^{-1}$, $200 \mathrm{~mm} \mathrm{~s}^{-1}$ and $1000 \mathrm{~mm} \mathrm{~s}^{-1}$. Next, pictures of the running tracks on the discs were taken with an optical microscope at the location where the grease had just been overrolled by the ball. These pictures are also shown in Figs. 3 and 4 just below the corresponding friction curve. With LP1 in Fig. 3a, a uniform thick layer of lubricant is left in the rolling track at $20 \mathrm{~mm} \mathrm{~s}^{-1}$. This gets gradually removed as the speed is increased, until the maximum speed of $1000 \mathrm{~mm} \mathrm{~s}^{-1}$ when only a dispersion of oil droplets is left in the track, possibly separated by thickener particles.

The equivalent pictures for LPE grease are shown in Fig. 4. As in LP1, the morphology of the film deposit changes as the speed is increased, from a grainy structure to a gradually fluid-like appearance, until only oil drops are found in the track at the maximum speed of $1000 \mathrm{~mm} \mathrm{~s}^{-1}$. However, the deposited film at low speeds looks patchier and thinner than in LP1.

\subsection{Friction with Additised Base Oils and Greases}

The influence of oleic acid in the custom greases was investigated by comparing the friction results obtained with additised and non-additised base oils and greases.
Figure 5 plots the curves obtained at $80{ }^{\circ} \mathrm{C}$, the test temperature at which the effect of oleic acid was the most apparent. Friction is evidently reduced in boundary and partly mixed lubrication conditions when oleic acid is used in the base oils of LP1, LPE and LM1. In contrast, the friction behaviour of additised and non-additised greases appears to be practically the same, i.e. no beneficial effect of oleic acid is apparent under these conditions.

\subsubsection{Film Thickness}

Measured grease film thickness is plotted against entrainment speed in Fig. 6. It can be noticed that the film thickness for all the LP greases, as well as LM1 and LM2 greases, initially decreases with increasing entrainment speed, from a value of $\approx 150 \mathrm{~nm}$ to a minimum value of $\approx 70 \mathrm{~nm}$. From here on, the film thickness starts increasing with speed with a slope which is close to 0.7 in the $\log -\log$ plot, i.e. in the manner that would be expected from the EHL theory for oils. It can be noted that the speed at which the minimum film thickness is found with the LP greases decreases with increasing base oil viscosity. LPE film thickness behaviour clearly diverges from this common trend. At $5 \mathrm{~mm} \mathrm{~s}^{-1} \mathrm{LPE}$ forms a film of $\approx 120 \mathrm{~nm}$. However, this decays very rapidly with increasing speed, reaching the minimum value of $24 \mathrm{~nm}$ at a speed of only $25 \mathrm{~mm} \mathrm{~s}^{-1}$. The corresponding transition in LP1, with the same base oil viscosity, occurs at a higher speed between 100 and $200 \mathrm{~mm} \mathrm{~s}^{-1}$.

\section{Discussion}

Based on the comparison between the experimental results obtained with the lithium greases and their base oils (Figs. 3, 4), two distinct operating regions can be identified 
(a)
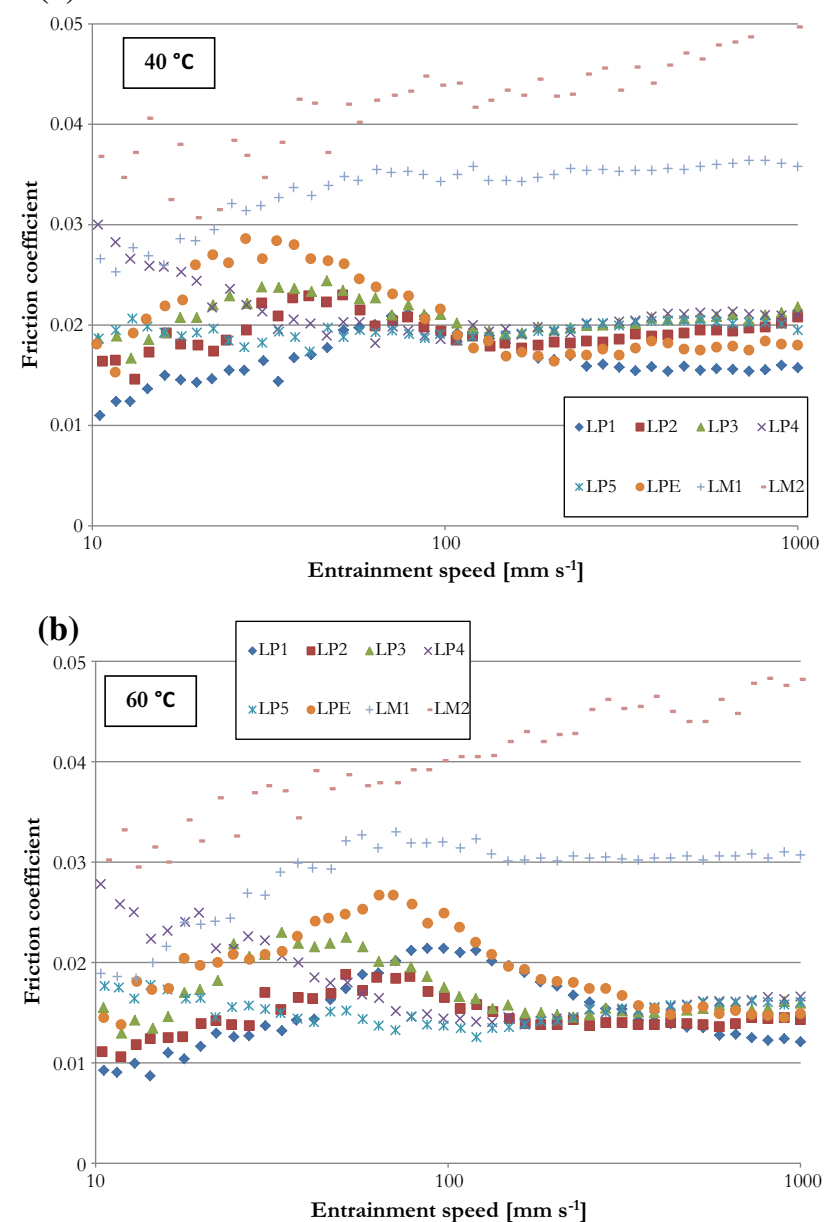

(c)

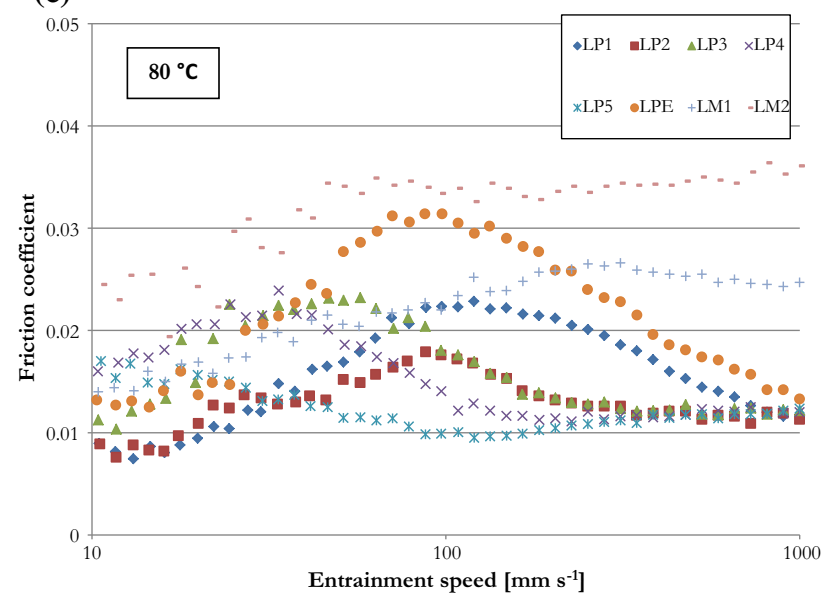

Fig. 2 Friction curves of custom greases at a $40{ }^{\circ} \mathrm{C}, \mathbf{b} 60{ }^{\circ} \mathrm{C}, \mathbf{c} 80^{\circ} \mathrm{C}$ plotted against entrainment speed

in the friction behaviour of greases. At sufficiently high speeds (past the friction curve bump), the friction behaviour of the tested lithium greases is practically identical to that of their base oils. Clearly, within this oil-dominated region, it is mostly the base oil characteristics that determine grease friction. Below a certain 'transition speed', lithium grease friction decreases with decreasing speed and is lower than that of the corresponding base oil. In addition, in this region, grease film thickness increases with decreasing speed (Fig. 6). This characteristic low-speed behaviour of greases, referred to in the literature as 'inverse-Stribeck'-like [20], is the opposite to that commonly observed with oils, where, within the mixed lubrication regime, friction increases with decreasing speed due to a drop in film thickness and the resulting greater number of asperities coming into contact, as also observed in this study (Figs. 3, 4). Clearly, the lithium thickener has a significant impact on the grease behaviour in this lowspeed region, and hence it is apt to refer to it as the thickener-dominated region. The general overall trends described above are in line with those reported previously by the current authors [19] and others [20,21] for lithium greases. However, rather than just revealing the general trends, the systematic nature of the present study allows for a more detailed discussion on the influence of base oil properties on grease friction, which can in turn help to provide further insight into the fundamental mechanisms of grease lubrication.

\subsection{Effect of Base Oil Viscosity}

The effect of base oil viscosity on friction can be examined by comparing the behaviour of the lithium-PAO (LP) greases, or that of the lithium-mineral oil (LM) greases, since each of these groups contains greases made with the same type of base oil but different viscosities. Figure 2, where the friction results are plotted against the entrainment speed, indicates some basic trends in this respect, in that for example the transition point (i.e. at the curve bump) between the thickener-dominated, low-speed and oil-dominated, high-speed regions on the LP greases moves to higher speed with decreasing base oil viscosity. However, no obvious correlation between the base oil viscosity and the absolute value of friction is apparent in these figures. Since base oil viscosity affects film thickness as well as friction, a better way to investigate the potential mechanisms at play is through relating the obtained friction results to some parameter related to contact film thickness. Figure 7 plots the friction measurements for the LP and LM greases against the nominal specific film thickness $\Lambda$, i.e. the specific film thickness calculated using the base oil properties only, not accounting for any influence of the thickener. Although the film thickness calculated in this way is clearly not the actual one in the contact within the thickener-dominated region (see Fig. 6), it is used here instead of the actual grease film thickness, which cannot be predicted using standard EHL film thickness equations, as it is relatively easy to calculate and hence useful for illustrating basic correlations. The nominal $\Lambda$ ratio used 
Fig. 3 Friction curves of LP1 grease and base oil at a $40{ }^{\circ} \mathrm{C}$, b $60{ }^{\circ} \mathrm{C}$, c $80{ }^{\circ} \mathrm{C}$; MTM disc micrographs in $\mathbf{a}$
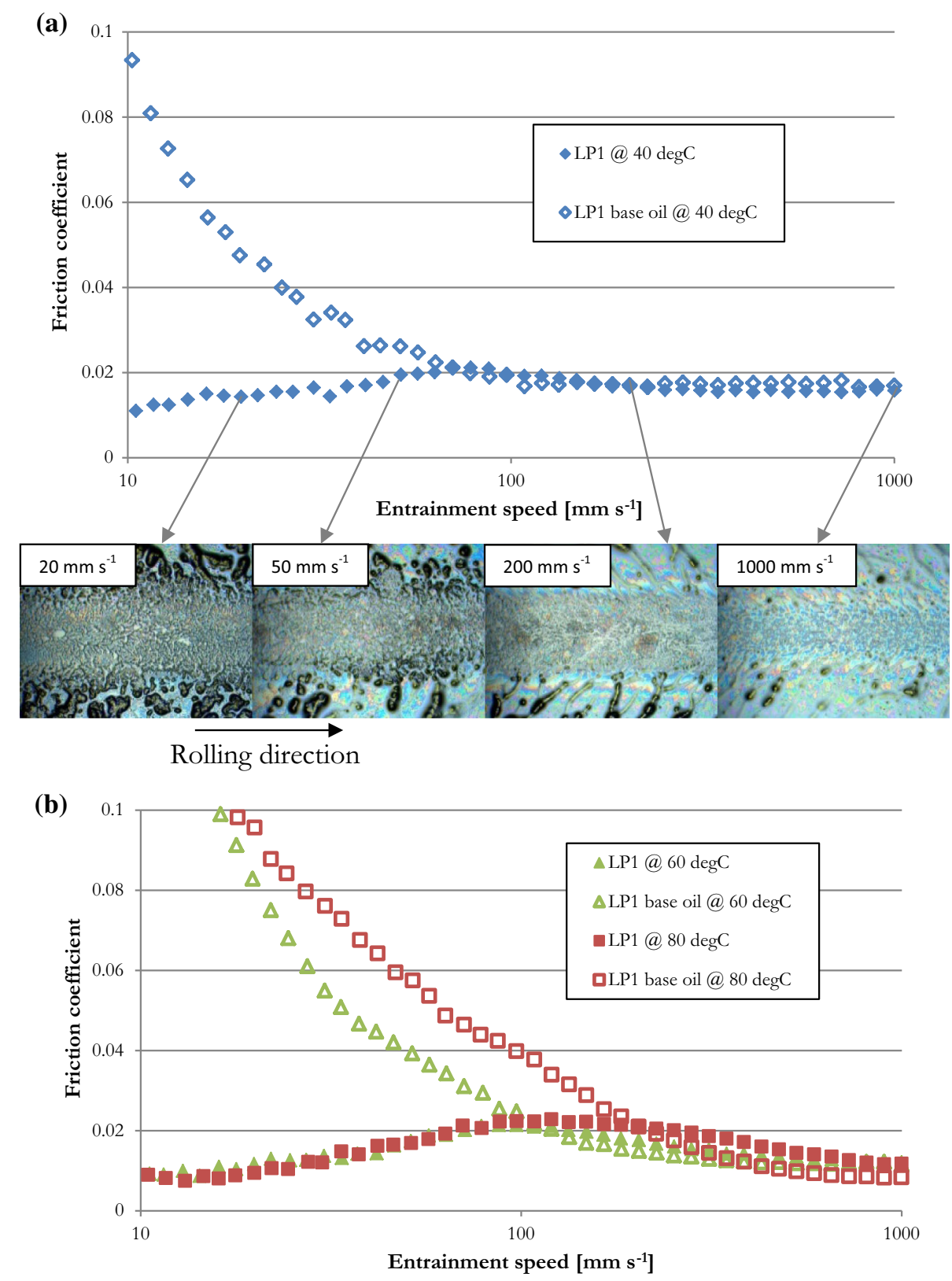

here is therefore calculated as the ratio of the film thickness estimated using the Hamrock-Dowson equation [28], with the base oil viscosity as measured at the temperature of each test, the oil pressure-viscosity values stated in Table 3, and the composite $\mathrm{Rq}$ surface roughness of the ball and disc specimens measured as $18.5 \mathrm{~nm}$. Although $\Lambda$ is a dimensionless parameter, the reader should be aware that the friction versus $\Lambda$ relationship shown in Fig. 7 is not intended for use in general predictions of absolute friction in lithium-PAO greases under other operating conditions resulting in the same $\Lambda$ ratios, not least because all current results are generated under one contact pressure and one surface roughness, and changing either of these is likely to have effects that are not accounted for by the nominal $\Lambda$ value alone.

The effect of base oil viscosity on grease friction is now more apparent. Measured grease friction for LP greases is correlated with the PAO base oil viscosity so that friction values are similar at a given value of nominal $\Lambda$ and form a common 'master' friction versus $\Lambda$, inverse-Stribeck-like curve (Fig. $7 \mathrm{a}-\mathrm{c}$ ). For all five LP greases and all three test temperatures, the location of the bump in the friction curves corresponds to the same friction value and to a relatively constant $\Lambda$ value (1-2) for all LP greases. This clearly suggests that the point of transition between the two operating regions is determined by the base oil film 
Fig. 4 Friction curves of LPE grease and base oil at a $40{ }^{\circ} \mathrm{C}$, b $60{ }^{\circ} \mathrm{C}$, c $80{ }^{\circ} \mathrm{C}$; MTM disc micrographs in a

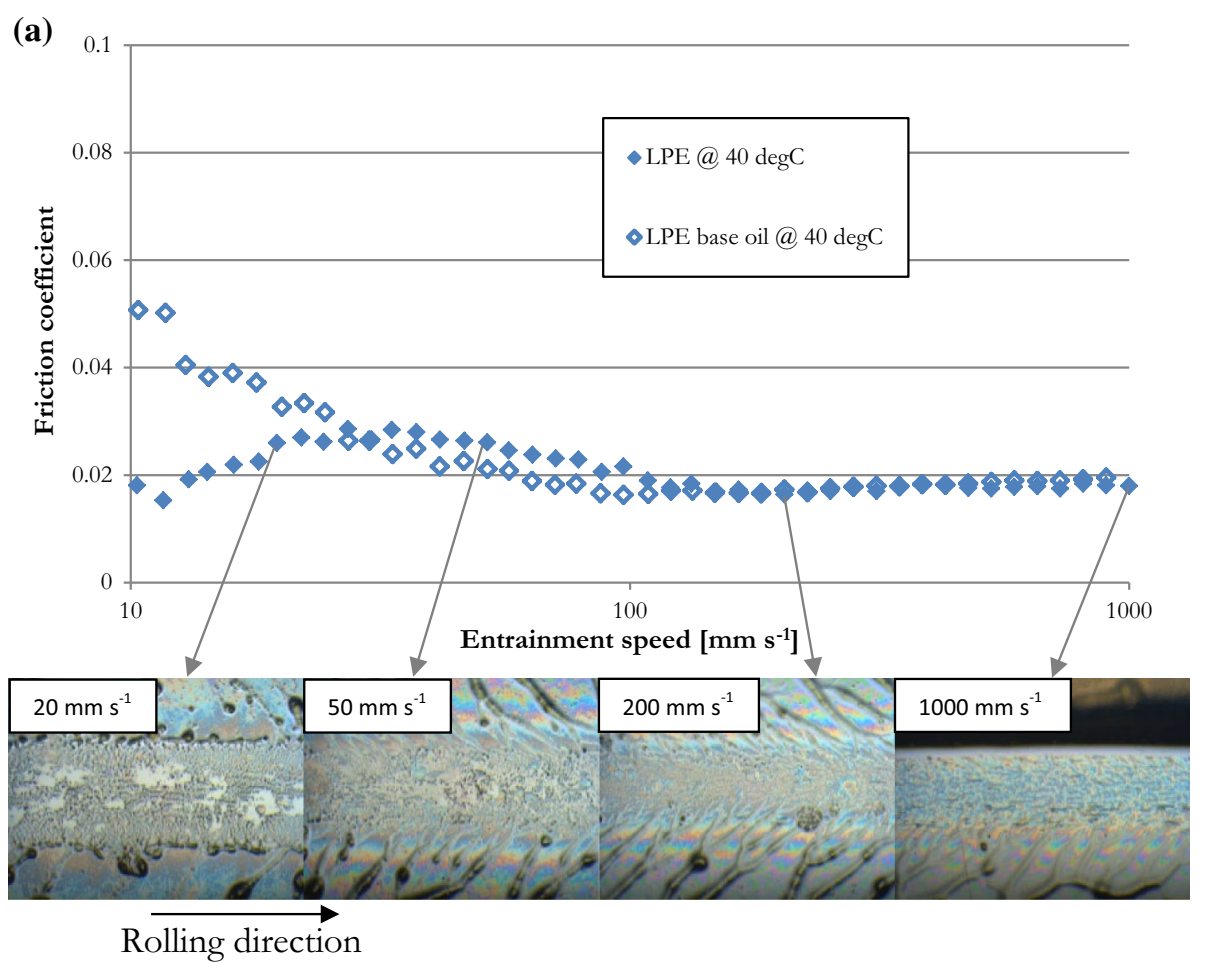

(b)

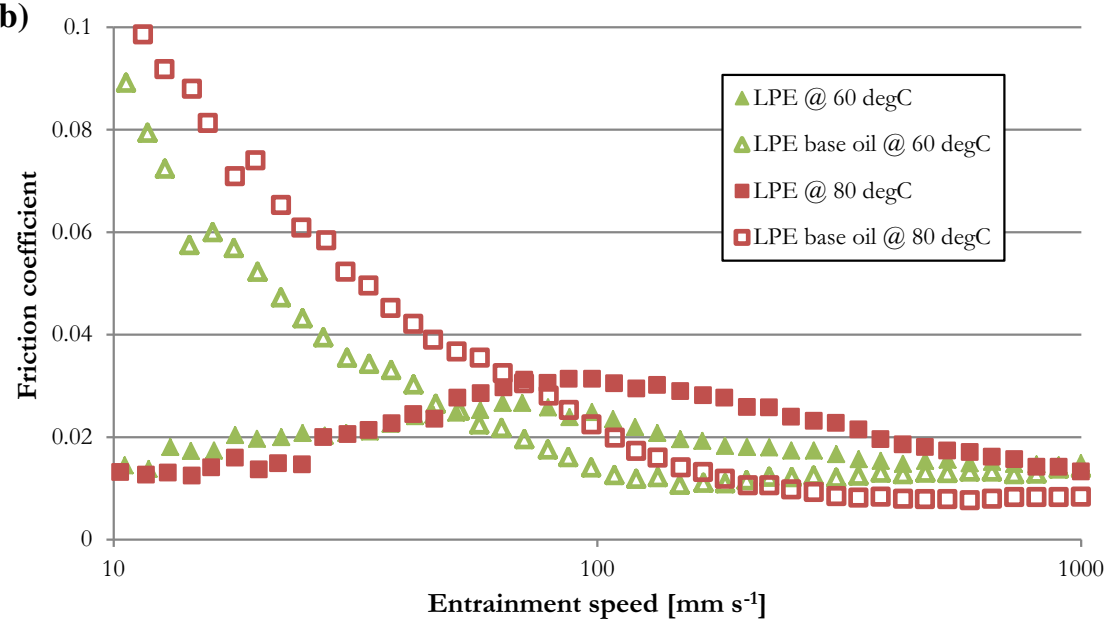

thickness at the prevailing contact conditions. This behaviour seems to be in line with that reported by Kanazawa et al. [22], who proposed that for a given thickener, the mechanism of grease lubrication is such that it is the characteristic 'transition film thickness', and not the 'transition speed', that determines the demarcation point between the thickener-dominated and the oil-dominated regions in the tribological behaviour of greases. Indeed, this is further confirmed by Fig. 6, where it is shown that the measured film thickness at the transition speed, above which the curve becomes linear, is comparable for all LP greases.

Distinct regions may be identified on the friction versus nominal $\Lambda$ ratio curve for the LP greases. At $\Lambda$ ratios higher than the transition point demarking the oil- and the thickener-dominated regions, the friction coefficient behaves in a manner that is relatively well established for lubricating oils. In full-film EHL conditions, at $\Lambda$ values of about 5 and over, the friction coefficient is in the range of 0.01-0.02, which, at the applied Hertz contact pressure of $0.96 \mathrm{GPa}$, corresponds to a maximum shear stress range of 10-20 MPa for all PAO-based greases and temperatures tested. The friction versus $\log \Lambda$ plot produces a straight line within this region, as may be expected at these shear stresses. At the highest speeds (the highest $\Lambda$ values in Fig. 7), some thermal effects may occur within the contact, however small, reducing the effective contact friction further. As $\Lambda$ decreases from 5 down to $\Lambda \approx 1-2$, which 

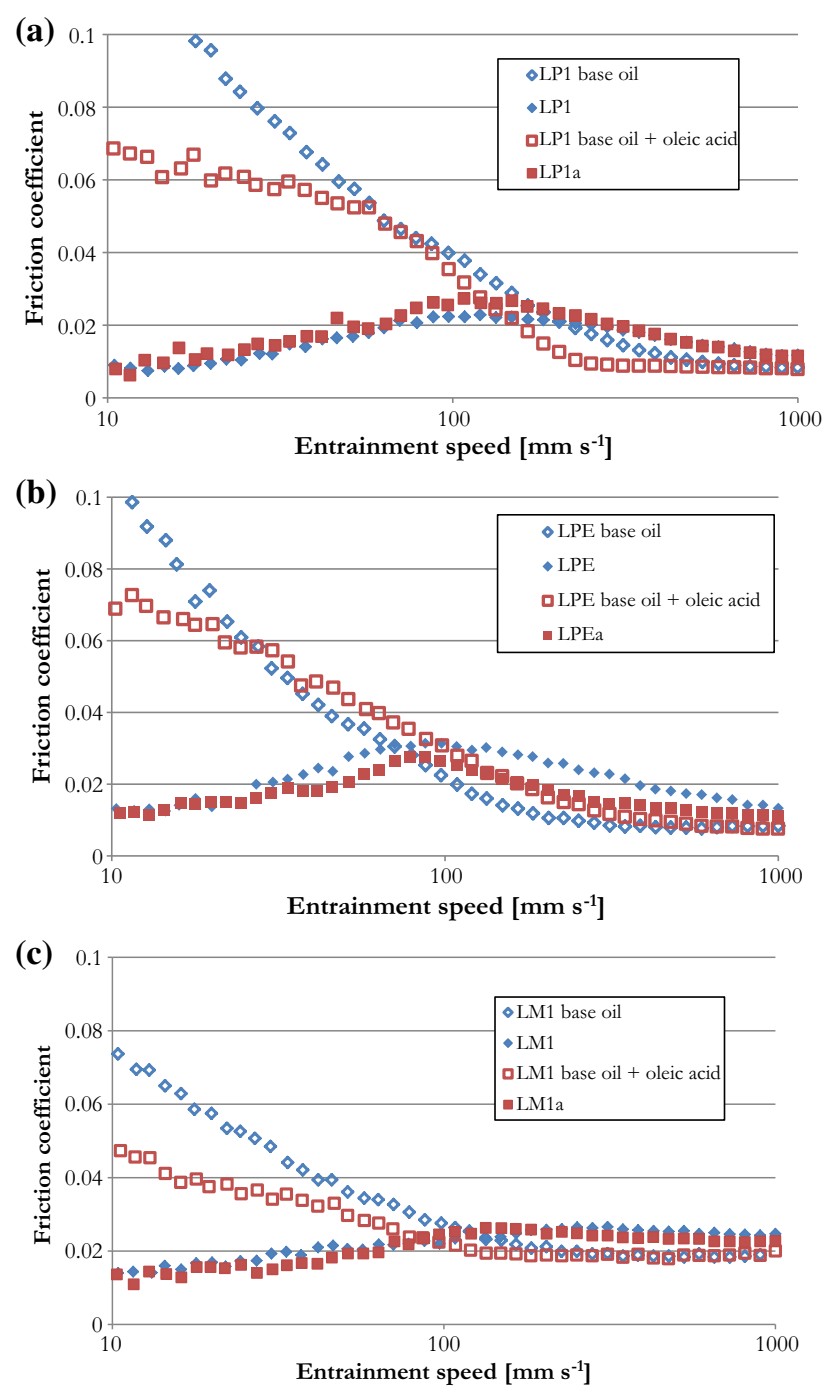

Fig. 5 Friction curves with a LP1 and LP1 base oil, b LPE and LPE base oil, c LM1 and LM1 base oil with and without oleic acid at $80{ }^{\circ} \mathrm{C}$

marks the transition point between the thickener and oildominated regions, friction increases as the contact enters mixed regime. This again is in line with the behaviour expected of the base oil alone as is evident in Figs. 3 and 4, where the frictional behaviour of greases and their base oil is compared. As $\Lambda$ decreases further, from $1-2$ at the transition point down to about $\Lambda=0.2$, friction decreases linearly with decreasing $\log \Lambda$ for all lithium-PAO greases tested, but with the gradient that is larger than that observed in the full-film region. The mechanisms responsible for friction within this region are likely to be rather complex. On the one hand, Fig. 6, all be it at a lower temperature of $22{ }^{\circ} \mathrm{C}$, shows that within this region, the film thickness increases from about $80 \mathrm{~nm}$ to approximately $150 \mathrm{~nm}$ with decreasing speed, so that the effective shear rate decreases considerably and some drop in friction may be expected from this. However, it is not possible to say whether this is the dominant friction mechanisms, not least because some contribution to friction from roughness effects may still be present, even if a full lift occurs, in a similar manner reported for oils [31, 32], and this contribution will also decrease as speed decreases. Moreover, in this region the lubricating film is likely to be made of a concentrated mixture of thickener and base oil, which will have its own characteristic high-pressure rheology. However, a thorough understanding of the effect of high-pressure rheology on friction, which is currently a subject of fierce debate even for simple base oils [33], is outside of the scope of this paper. In any case, grease friction is clearly lower than that of the base oils throughout this region, suggesting that the film enhancement through thickener action is clearly having a positive effect by reducing asperity contact. Finally, it should be noted that at even lower nominal $\Lambda$ values, the nature of the lubricant film and the resulting contact friction response may change. Some evidence of this is present in Fig. 7c, showing friction results at the highest temperatures, and hence the lowest nominal $\Lambda$, where friction coefficient appears to reach a plateau at a very low value of less than 0.01 , with no further reduction with decreasing $\Lambda$. The reasons for this are not entirely clear, but it may suggest that the contact is lubricated by some low-friction solid-like deposited film leading to a low, constant friction.

In contrast to the LP greases, the mineral oil-based greases LM1 and LM2 produce values of friction that are very different even when compared at the same nominal $\Lambda$ (Fig. 7d-f). However, unlike the PAO base oils, the mineral base oils of LM1 and LM2 greases are likely to contain very different chemical compounds, as mineral oils are generally complex mixtures of different components [34]. The investigation into the effect of base oil viscosity on friction for these two greases is therefore somewhat futile, as the two mineral oils of LM1 and LM2 cannot be directly compared.

\subsection{Effect of Base Oil Type}

The effect of base oil type on friction can be investigated by comparing the behaviour of greases made with base oils of similar viscosity but different type, namely LP1 with LM1 and LPE, and LP3 with LM2. The friction results obtained with these two groups of greases are plotted against the entrainment speed in Fig. 8. It is immediately apparent that the mineral oil-based LM1 and LM2 greases give higher friction than the PAO-based LP1 and LP3, respectively, at all speeds and temperatures tested. Such behaviour is expected at high speeds, where grease friction is determined by its base oil properties as discussed above. Indeed, EHL friction with oil is known to be strongly dependant on the molecular structure of the oil, including 
Fig. 6 Film thickness measurements of greases versus entrainment speed at ambient temperature $\left(22 \pm 1{ }^{\circ} \mathrm{C}\right)$

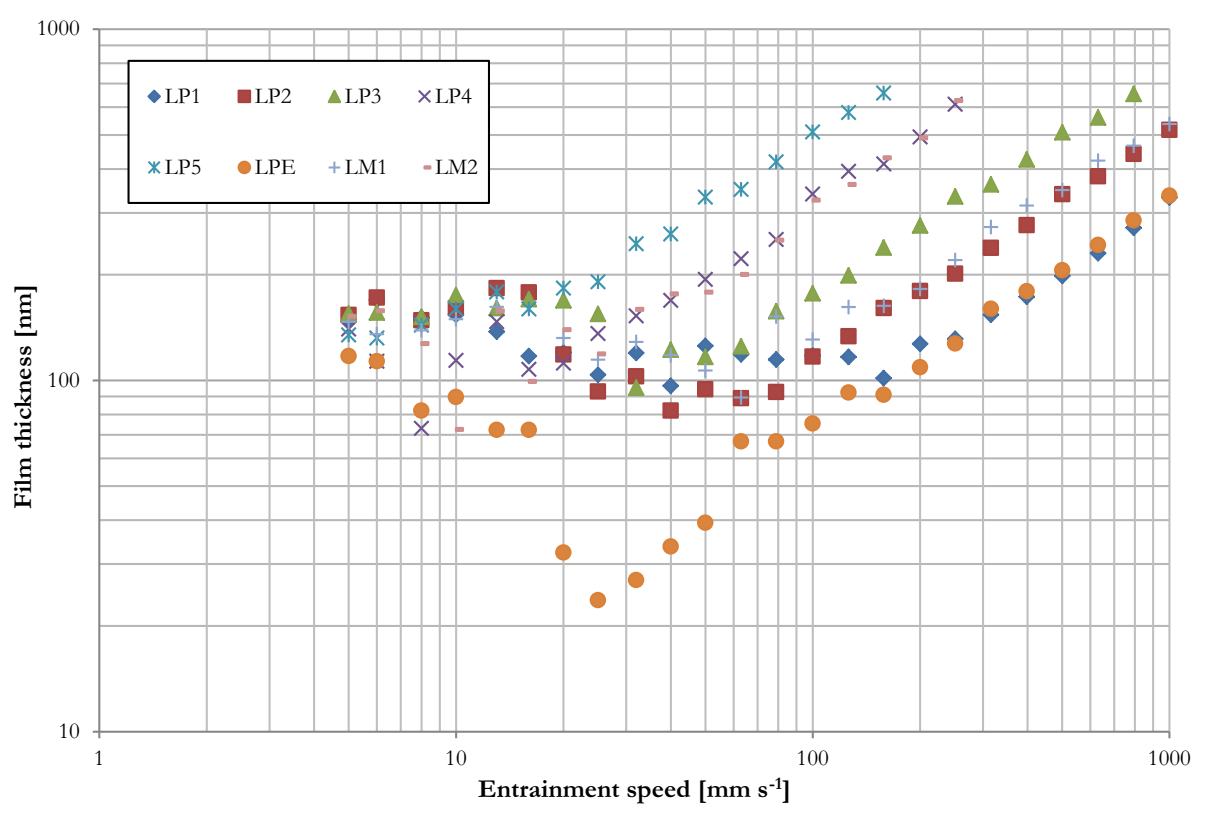

molecular shape and flexibility, since these characteristics determine the 'fluid' friction arising from shearing the film molecular layers at high pressure [35-37]. Low shear strength, and thus low friction, is favoured by oils containing linear, aligned and flexible molecules. These are all common features of the alkyl chains that compose the PAO oils, which consequently are expected to produce lower friction than mineral oils [37].

However, the reasons for the higher friction observed with the mineral oil-based greases within the low-speed, thickener-dominated region are somewhat less obvious, given that all greases were formulated with the same lithium thickener. In addition, the minimum film thicknesses given by all these greases are very similar (Fig. 6), so that the observed differences in friction cannot be attributed to different degrees of asperity interaction. This result clearly suggests that the oil type does have an influence on friction even in the thickener-dominated region. Within this region, the friction coefficient seems to increase approximately linearly with $\log$ of speed, again suggesting that the contact is not lubricated by a solid layer of thickener only, but most likely some concentrated mixture of thickener and base oil. Consequently, within this region, the relative friction coefficients of greases also follow the trend that may be expected from their corresponding base oil properties, being lower for PAO-based greases than for the equivalent mineral oilbased greases.

Like the mineral oil-based LM1 grease, the ester-containing LPE grease also gives higher friction than the PAObased LP1 at low speeds. In this case, however, the result can largely be attributed to the significantly lower film thickness obtained with LPE within this region, as evident from Fig. 6, and hence increased contribution of asperity contacts to the overall friction. The film thickness results show that effectively, the extent of the thickener-dominated region with LPE grease is smaller than that with LP1. These differences in film thickness and friction between LP1 and LPE greases are clearly evident, despite the fact that the compositions of LPE and LP1 are very similar, and only differ by the presence of $20 \%$ of ester oil in the formulation of LPE. A similar trend was previously observed by the authors with commercial greases of the same basic lithium thickener-ester oil composition [19]. Various characteristics of ester-based greases have been proposed in literature as negatively affecting their lubrication behaviour [38, 39], with increased propensity for contact starvation suggested as perhaps the most significant factor [40]. However, in the current study the onset of starvation can be excluded, as the tests were performed in fully flooded conditions by directing the supply of grease to the contact by means of a grease scoop. Instead, it is thought that it is the characteristic structure of the ester-containing lithium greases that is responsible for the observed decreased film thickness, and in turn the increased friction. With this in mind, the structure of the lithium thickener of the test greases was observed in an SEM. The SEM samples were prepared by first spreading a thin layer of each grease on a cylinder mount and then repeatedly flushing the grease layers with toluene to dissolve and separate the base oil until only the residual thickener was left on the mounts. An agar sputter coater was used to cover the thickener samples with gold before the SEM analysis to improve conductivity. Figure 9 shows SEM images of selected 
(a)

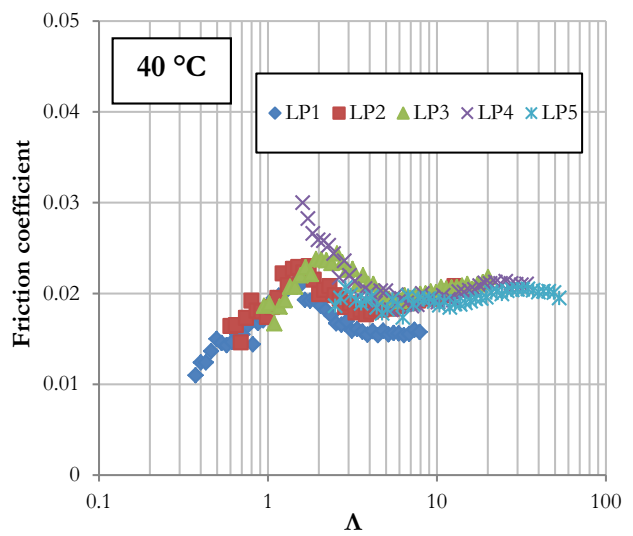

(c)

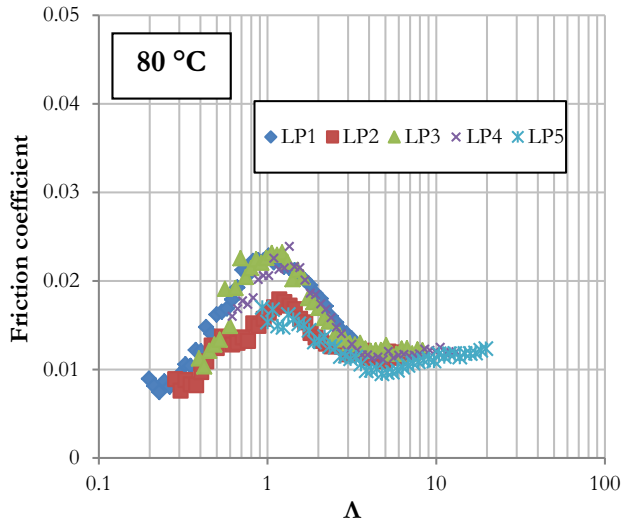

(e)

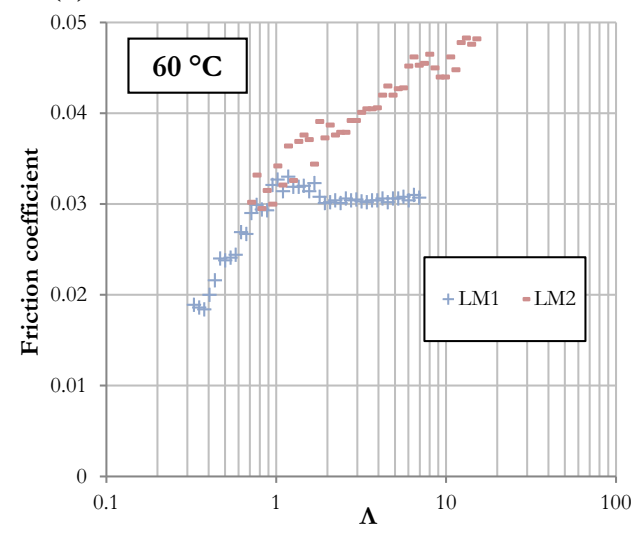

Fig. 7 Effect of base oil viscosity on grease friction-comparison of friction curves of lithium-PAO (LP) greases at a $40{ }^{\circ} \mathrm{C}, \mathbf{b} 60^{\circ} \mathrm{C}$, c $80{ }^{\circ} \mathrm{C}$ and of lithium-mineral (LM) greases at d $40{ }^{\circ} \mathrm{C}$, e $60{ }^{\circ} \mathrm{C}$,

lithium thickener samples, including those of the custom LP1 and LPE greases tested here, as well as the commercial PAO- and ester-based greases tested in the previous study [19], denoted as LiPAO and LiEs respectively. Although the shown thickener structure is not necessarily the one existing in the contact, these images can be used to make basic relative comparison in terms of grease (b)

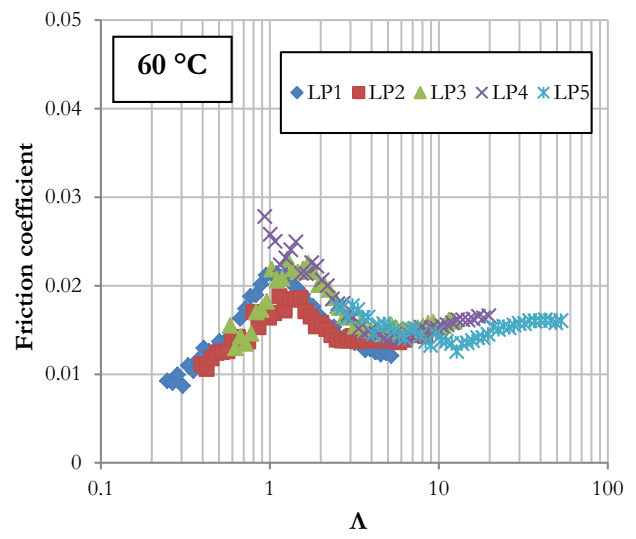

(d)

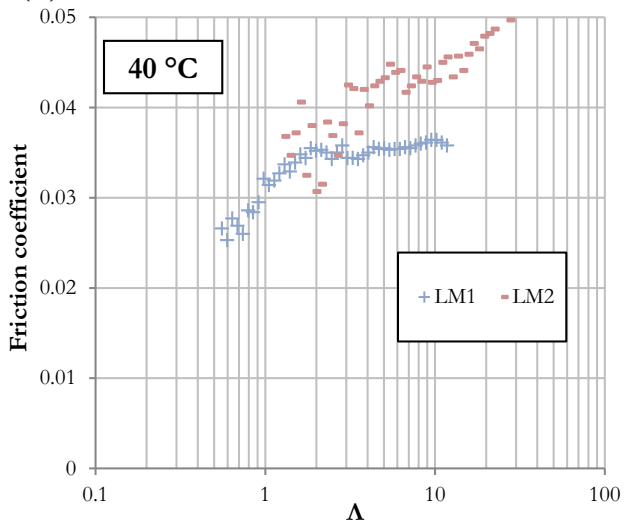

(f)

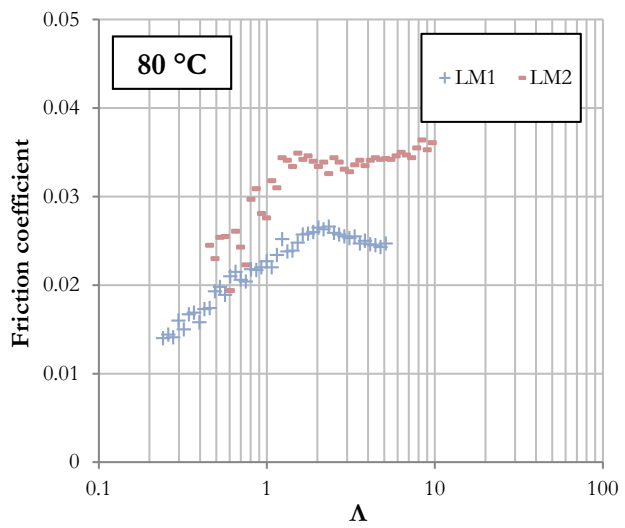

f $80{ }^{\circ} \mathrm{C}$ plotted against calculated nominal specific film thickness $\Lambda$ (i.e. the film thickness calculated based on the base oil properties alone)

thickener structure. It is clearly evident that the lithium fibres of the PAO-based greases (LP1 and LiPAO) are much thicker and longer than those of the ester-based LPE and LiEs greases. All the remaining non-ester greases tested in this work display very similar fibre structure to that of LP1, as is evident in the examples of LP3 and LM2 in Fig. 9. Literature [40-42] suggests that shorter lithium 
Fig. 8 Effect of base oil type on grease friction-comparison of friction curves of LP1, LPE and LM1 at a $40{ }^{\circ} \mathrm{C}, \mathbf{b} 60^{\circ} \mathrm{C}$, c $80{ }^{\circ} \mathrm{C}$, and of LP3 and LM2 at d $40{ }^{\circ} \mathrm{C}$, e $60{ }^{\circ} \mathrm{C}$, f $80^{\circ} \mathrm{C}$ plotted against entrainment speed (a)

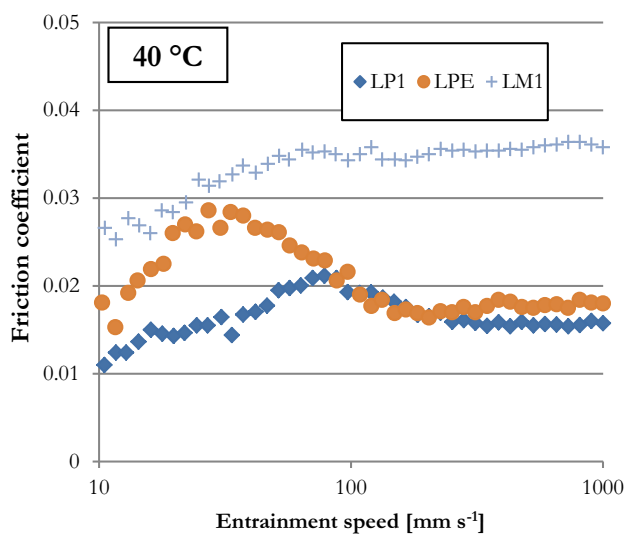

(c)

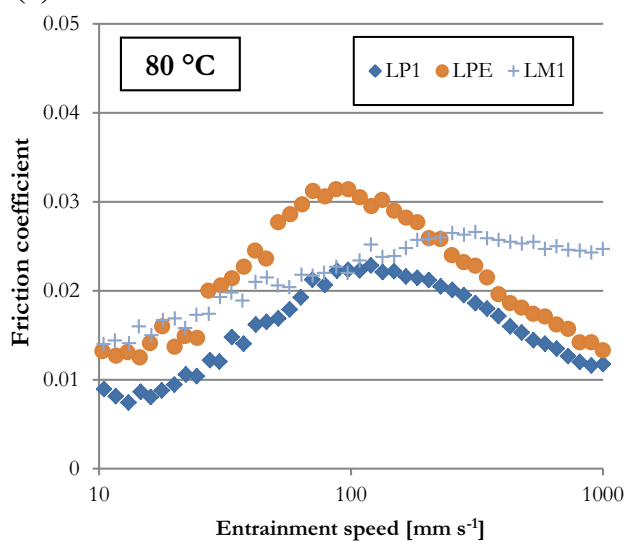

(e)

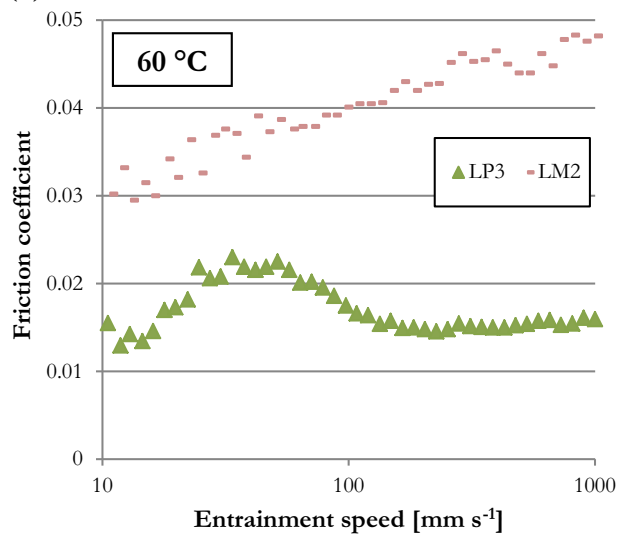

(b)

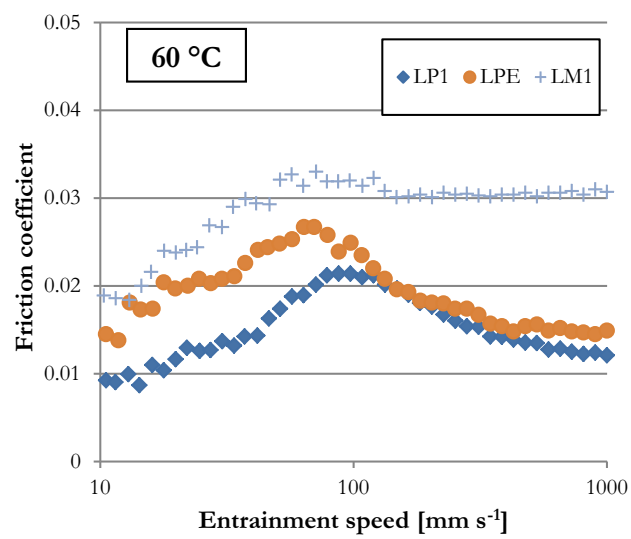

(d)

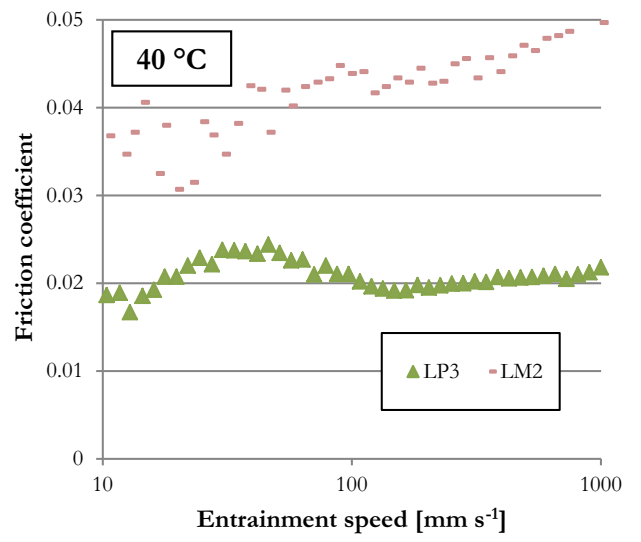

(f)

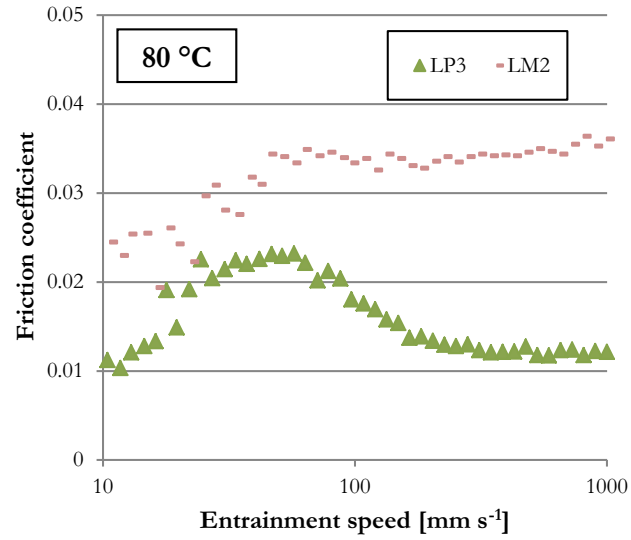

thickener fibres can produce thinner films at low speeds, and consequently higher friction due to increased asperity contacts [43]. Kanazawa et al. [22] suggest that the 'transition film thickness' for a given grease, and hence the extent of the region where thickener film enhancement is evident, is determined by the ratio of thickener fibre size to the film thickness obtained by the base oil alone, i.e. the thickener-dominated zone ends when the film thickness attainable with the base oil alone exceeds a characteristic dimension of the thickener. Indeed, in the present study, a much lower transition film thickness value was found with LPE, while approximately the same value was recorded for the LP and LM greases. Therefore, the results suggest that the thinner lithium fibres obtained with ester greases are responsible for the diminished film enhancement at low speeds and the associated increase in friction due to asperity contact. This assertion is also supported by the differences observed in the comparison between the deposited grease film in LP1 (Fig. 3) and LPE (Fig. 4) during the friction tests. 
Fig. 9 SEM micrographs of lithium microstructure with LP1, LiPAO and LP3 (PAObased greases), LPE and LiEs (ester-containing greases) and LM2 (mineral oil-based grease)
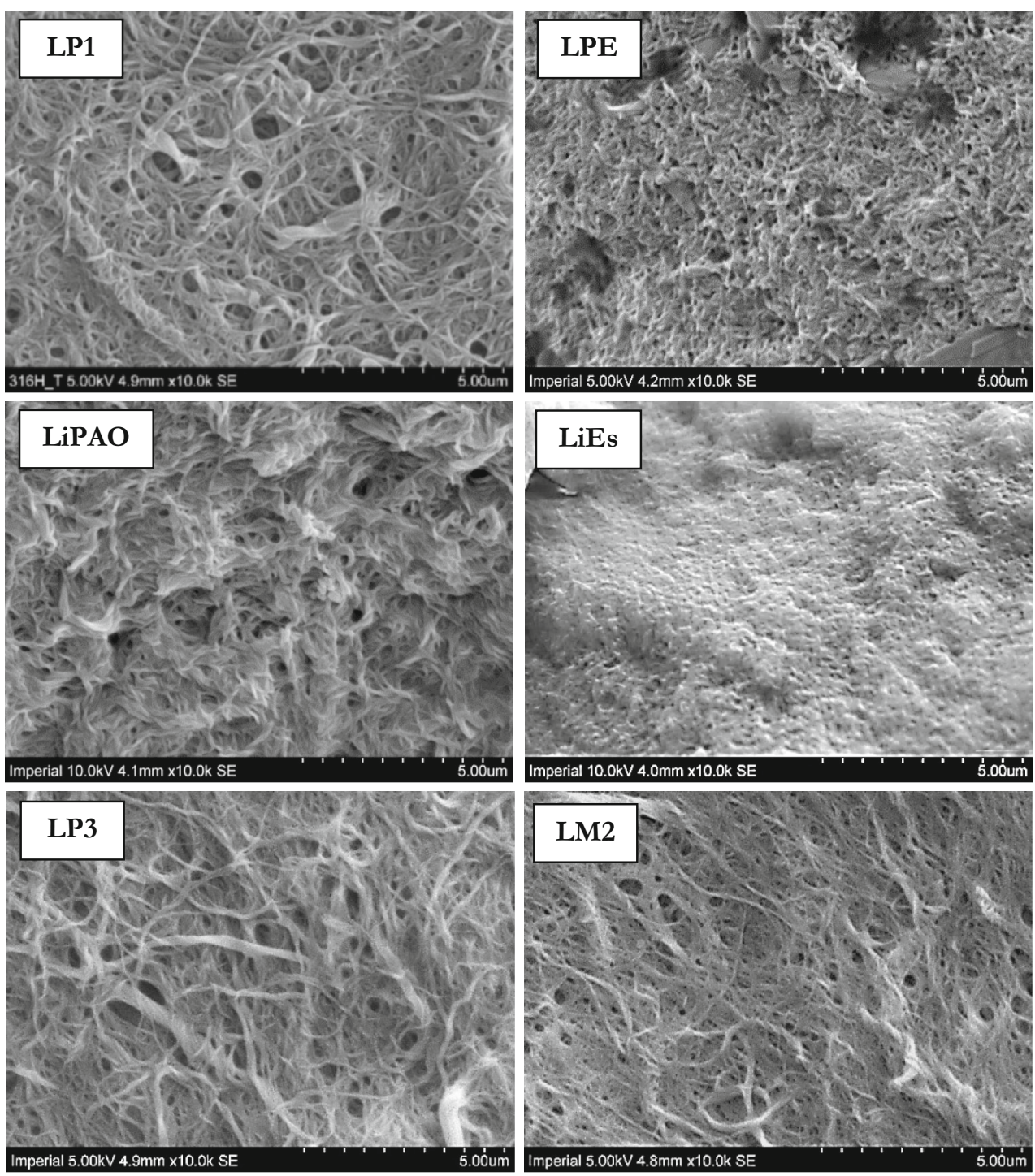

Based on the current results, the potential mechanisms through which base oil type may influence lithium grease friction can be summarised as follows:

- At relatively high speeds, lithium grease friction is largely determined by the base oil frictional properties so that, for equivalent specific film thicknesses, greases based on low-friction synthetic oils have lower friction than the mineral oil equivalents;

- Within the low-speed, thickener-influenced region, the contact is lubricated by a concentrated mixture of lithium thickener fibres and base oil. If the film thickness is sufficient to fully separate the surfaces, friction is determined by the rheological properties of this mixture, so that once more low-friction synthetic oil-based greases produce lower friction than the equivalent mineral oil-based ones;

- In addition, base oil type can affect the lithium thickener structure formed during grease manufacture, which in turn determines the extent of the thickenerdominated region over which the thickener has beneficial effects on film thickness and friction. In particular, oils that promote formation of smaller, shorter lithium thickener fibres, such as was observed with ester oils in this study, can result in a decrease in film enhancement offered by lithium greases at low speeds, which in turn, depending on prevailing surface roughness, can cause an increase in friction.

\subsection{Comparison of Low-Friction Model Greases and Their Fully Formulated Commercial Equivalents}

The results of the present study indicate that, as far as base oil properties are concerned, lithium greases formulated with a relatively low viscosity PAO base oil produce lower friction than greases made with mineral or ester oils. It is 
interesting to compare these results to those obtained with an equivalent fully formulated commercial lithium grease, based on a PAO base oil of similar viscosity, which was found to produce the lowest friction out of a large set of commercial greases tested in the previous study by the authors [19]. To this end, the friction curves of the custom LP1 grease and the commercially available lithium-PAO grease, denoted as LiPAO and marketed as a low-friction grease [19], are plotted together in Fig. 10 for comparison. The curves are remarkably similar, which verifies that the model greases tested in this paper are representative of their commercial counterparts, and confirms the suitability of lithium thickener and PAO oil as a potential low-fiction formulation, as initially suggested by the previous study with commercial greases. In addition, the fact that the two greases produce very similar friction despite the fact the commercial LiPAO grease is very likely to contain additives in its formulation, also shows that its low-friction performance is primarily determined by the basic formulation (base oil and thickener) rather than the additive package, at least under the conditions considered here. This observation is further supported by the result obtained with the LP1 grease additised with oleic acid, a friction modifier, which showed no significant effect on the frictional performance of LP1 (Fig. 5). In contrast, oleic acid did show a reduction in friction with base oils within the lowspeed, mixed lubrication region where metal-to-metal contact may be expected to occur in case of oil lubrication. The most plausible reason for the apparent ineffectiveness of oleic acid in this grease formulation is that at these low speeds, where oleic acid would normally be expected to act, the thick film formed by the lithium grease already provides low friction due to much higher real $\Lambda$ values than attainable with corresponding base oils, rendering the oleic acid somewhat redundant. Obviously, these results are not exhaustive and do not exclude the influence of oleic acid, or other friction modifiers, on friction under different

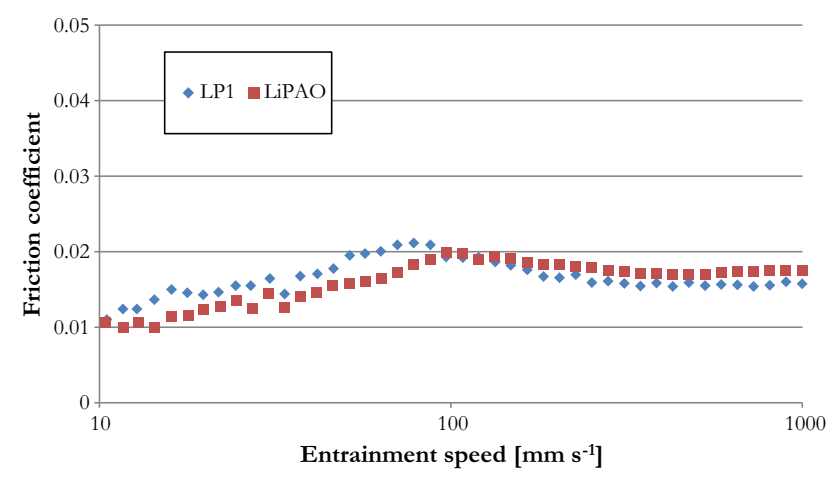

Fig. 10 Friction coefficient of custom LP1 and commercially available LiPAO greases (lithium-thickened greases formulated with a low-viscosity PAO oil) at $40{ }^{\circ} \mathrm{C}$ contact conditions. However, they do suggest that under certain conditions, additive-free grease formulations may be just as acceptable as their fully formulated, and more expensive, equivalents.

\section{Conclusions}

The friction behaviour of a series of model lithium-thickened greases, manufactured with a systematically varied base oil type and viscosity, was studied under fully flooded conditions using ball-on-disc tribometers. The main conclusions can be summarised as follows:

- Lithium greases display two operating regions: at relatively high speeds, grease behaviour is dominated by the properties of its base oil; below a certain transition speed, there exists a thickener-dominated region where grease friction decreases and film thickness increases with decreasing entrainment speed, trends that are opposite to those exhibited by the corresponding base oils. The transition between these two regions occurs at a characteristic value of nominal film thickness, which appears to be affected by the size of the lithium thickener fibres in a given grease;

- Influence of base oil viscosity on lithium grease friction: for the tested PAO-based greases, the lower the base oil viscosity, the higher is the speed up to which the grease operates in the thickener-dominated region. The influence of oil viscosity on grease friction correlates well with the predicted nominal specific film thickness $(\Lambda)$ calculated with the base oil properties, i.e. grease friction versus nominal $\Lambda$ curves for all PAO viscosities tested are the same. Moreover, within the high-speed region, grease friction is well described by the Stribeck curve of its base oil, while within the thickener-dominated low-speed region, grease friction decreases with decreasing nominal $\Lambda$;

- Influence of base oil type on lithium grease friction: within the high-speed region, grease friction is dominated by the base oil properties, so that greases with PAO synthetic oils exhibit significantly lower friction than those based on the same viscosity mineral oils. Less expectedly, PAO-based lithium greases provide lower friction than their mineral oil equivalents even within the low-speed thickener-influenced region, suggesting that a concentrated lithium thickener-oil mixture is responsible for lubrication under these conditions and that its frictional properties are influenced by the base oil type. In addition, lithium greases containing ester oils were shown to produce thinner films and consequently higher friction than those containing PAO oils at low speeds; this was attributed 
to smaller lithium thickener fibres observed in esterbased greases;

- Under the test conditions employed in this study, the addition of oleic acid to model lithium greases did not result in further significant reduction in friction. Moreover, frictional performance of the non-additised model lithium-PAO grease and the fully formulated commercial equivalent was shown to be similar. These results suggest that, under the present test conditions, the low-friction properties of the lithium-PAO greases are largely derived from their thickener-oil combination rather than effects of any additive packages.

Acknowledgements The research leading to these results has received funding from the People Programme (Marie Curie Actions) of the European Union's Seventh Framework Programme FP7/20072013/under REA Grant agreement No. 612603. Remko Thijssen, SKF RTD, is kindly acknowledged for his help with the characterisation of the test greases.

Open Access This article is distributed under the terms of the Creative Commons Attribution 4.0 International License (http://creative commons.org/licenses/by/4.0/), which permits unrestricted use, distribution, and reproduction in any medium, provided you give appropriate credit to the original author(s) and the source, provide a link to the Creative Commons license, and indicate if changes were made.

\section{References}

1. Lugt, P.M.: Grease Lubrication in Rolling Bearings. Wiley, London (2013)

2. Lansdown, A.R., Gupta, R.: The influence of evaporation on grease life. In: NLGI Spokesm, pp. 148-153 (1985)

3. Booser, E.R., Wilcock, D.F.: Minimum oil requirements of ball bearings. Lubr. Eng. 9(3), 140-143 (1953)

4. Cousseau, T., Björling, M., Graça, B., Campos, A., Seabra, J., Larsson, R.: Film thickness in a ball-on-disc contact lubricated with greases, bleed oils and base oils. Tribol. Int. 53, 53-60 (2012)

5. Scarlett, N.A.: Use of grease in rolling bearings. Proc. Inst. Mech. Eng. Conf. Proc. 182(1), 585-624 (1967)

6. Cann, P.M.: Starvation and reflow in a grease-lubricated elastohydrodynamic contact. Tribol. Trans. 39(3), 698-704 (1996)

7. Godfrey, D.: Friction of greases and grease components during boundary lubrication. ASLE Trans. 7(1), 24-31 (1964)

8. Rong-Hua, J.: Effects of the composition and fibrous texture of lithium soap grease on wear and friction. Tribol. Int. 18(2), 121-124 (1985)

9. Palacios, J.M., Cameron, A., Arizmendi, L.: Film thickness of grease in rolling contacts. ASLE Trans. 24(4), 474-478 (1981)

10. Dyson, A., Wilson, R.W.: Film thicknesses in elastohydrodynamic lubrication of rollers by greases. In: Proceedings of the Institution of Mechanical Engineers, Conference Proceedings, vol. 184 (1969)

11. Cousseau, T., Graça, B., Campos, A., Seabra, J.: Experimental measuring procedure for the friction torque in rolling bearings. Lubr. Sci. 22(4), 133-147 (2010)

12. Gonçalves, D., Graça, B., Campos, A.V., Seabra, J.: On the friction behaviour of polymer greases. Tribol. Int. 93(Part A), 399-410 (2016)

13. Cyriac, F., Lugt, P.M., Bosman, R., Padberg, C.J., Venner, C.H.: Effect of thickener particle geometry and concentration on the grease EHL film thickness at medium speeds. Tribol. Lett. 61(2), 18 (2016)

14. Muennich, H.C., Gloeckner, H.J.R.: Elastohydrodynamic lubrication of grease-lubricated rolling bearings. ASLE Trans. 23, 45-52 (1978)

15. Cann, P.M., Doner, J.P., Webster, M.N., Wikström, V.: Grease degradation in rolling element bearings. Tribol. Trans. 44(3), 399-404 (2001)

16. Cann, P.M., Webster, M.N., Doner, J.P., Wikström, V., Lugt, P.: Grease degradation in R0F bearing tests. Tribol. Trans. 50(2), 187-197 (2007)

17. Wikström, V., Höglund, E.: Starting and steady-state friction torque of grease-lubricated rolling element bearings at low temperaturespart I: a parameter study. Tribol. Trans. 39(3), 517-526 (1996)

18. Wikström, V., Höglund, E.: Starting and steady-state friction torque of grease-lubricated rolling element bearings at low temperatures-part II: correlation with less-complex test methods. Tribol. Trans. 39(3), 684-690 (1996)

19. De Laurentis, N., Kadiric, A., Lugt, P., Cann, P.: The influence of bearing grease composition on friction in rolling/sliding concentrated contacts. Tribol. Int. 94, 624-632 (2016)

20. Cann, P.M.: Grease lubrication of rolling element bearings-role of the grease thickener. Lubr. Sci. 19(3), 183-196 (2007)

21. Cen, H., Lugt, P.M., Morales-Espejel, G.: On the film thickness of grease-lubricated contacts at low speeds. Tribol. Trans. 57(4), 668-678 (2014)

22. Kanazawa, Y., Sayles, R.S., Kadiric, A.: Film formation and friction in grease lubricated rolling-sliding non-conformal contacts. Tribol. Int. 109, 505-518 (2017)

23. Nolan, S.J., Zeitz, J.B.: Anhydrous lithium hydroxide dispersion: a new and efficient way to make simple and complex lithium greases. NLGI Spokesm. 71(8), 17-25 (2007)

24. Ishchuck, Y.L.: Lubricating Grease Manufacturing Technology. New Age International Publishers, New Delhi (2005)

25. Fish, G.: The development of energy efficient greases. Eurogrease 2, 6-17 (2015)

26. Rudnick, L.R., Shubkin, R.L.: Synthetic Lubricants and HighPerformance Functional Fluids, Revised and Expanded. CRC Press, New York (1999)

27. Walther, C.: The evaluation of viscosity data. Erdöl und Teer 7, 382-384 (1931)

28. Hamrock, B.J., Dowson, D.: Ball Bearing Lubrication: The Elastohydrodynamics of Elliptical Contacts. Wiley, London (1981)

29. Höglund, E.: Influence of lubricant properties on elastohydrodynamic lubrication. Wear 232(2), 176-184 (1999)

30. Bair, S.: High Pressure Rheology for Quantitative Elastohydrodynamics, vol. 54. Elsevier, Chicago (2007)

31. Guegan, J., Kadiric, A., Spikes, H.: A study of the lubrication of EHL point contact in the presence of longitudinal roughness. Tribol. Lett. 59(1), 22 (2015)

32. Guegan, J., Kadiric, A., Gabelli, A., Spikes, H.: The relationship between friction and film thickness in EHD point contacts in the presence of longitudinal roughness. Tribol. Lett. 64(3), 33 (2016)

33. Spikes, H., Jie, Z.: History, origins and prediction of elastohydrodynamic friction. Tribol. Lett. 56(1), 1-25 (2014)

34. Mortier, R.M., Fox, M.F., Orzulik, S.T.: Chemistry and Technology of Lubricants, 3rd edn. Springer, Berlin (2010)

35. Gunsel, S., Korcek, S., Smeeth, M., Spikes, H.A.: The elastohydrodynamic friction and film forming properties of lubricant base oils. Tribol. Trans. 42, 559-569 (1999)

36. Spikes, H.: Basics of EHL for practical application. Lubr. Sci. 27(1), 45-67 (2015)

37. Zhang, J., Tan, A., Spikes, H.: Effect of base oil structure on elastohydrodynamic friction. Tribol. Lett. 65(1), 13 (2016)

38. Cann, P.M.: Thin-film grease lubrication. Proc. Inst. Mech. Eng. Part J J. Eng. Tribol. 213(5), 405-416 (1999) 
39. Couronné, I., Vergne, P., Mazuyer, D., Truong-Dinh, N., Girodin, D.: Effects of grease composition and structure on film thickness in rolling contact. Tribol. Trans. 46(1), 31-36 (2003)

40. Cousseau, T., Graça, B.M., Campos, A.V., Seabra, J.H.O.: Influence of grease rheology on thrust ball bearings friction torque. Tribol. Int. 46(1), 106-113 (2012)

41. Kimura, H., Imai, Y., Yamamoto, Y.: Study on fiber length control for ester-based lithium soap grease. Tribol. Trans. 44(3), 405-410 (2001)
42. Lugt, P.M.: A review on grease lubrication in rolling bearings. Tribol. Trans. 52(4), 470-480 (2009)

43. Sakai, K., Tokumo, Y., Ayame, Y., Shitara, Y., Tanaka, H., Sugimura, J.: Effect of formulation of Li greases on their flow and ball bearing torque. Tribol. Online 11(2), 168-173 (2016) 